\title{
A Comparison of Efficacy of Nasal Septal Splints with Clip versus Nasal Packing after Septoplasty
}

https://doi.org/10.47210/bjohns.2021.v29i1.314

Piyush Kant Singh, ${ }^{1}$ Preeti Singh ${ }^{1}$

$\underline{\text { Introduction }}$

\section{ABSTRACT}

It has always been a concern of ENT surgeon to prevent post operative complications like nasal bleeding, septal hematoma and septal abscess after septoplasty. Traditionally nasal packing has been done to avoid these complications. Although the nasal pack itself has been a concern for several reasons, packing apart from causing breathing distress, has resulted in epiphora, dysphagia, sleep disturbance, post-operative pain, headache, septal infection, septal abscess and even toxic shock syndrome. Materials and Methods

This study has compared the efficacy of a newly designed septal splint with clip with nasal packs. This study was done on 60 patients, nasal packing was done in 30 patients and septal splints with clip were applied in 30 patients.

$\underline{\text { Results }}$

Post-operative pain, epiphora, dysphagia, dryness of mouth and sleep disturbance was found to be significantly less in patients with septal splints with clip as compared to those with nasal packing.

\section{Conclusion}

Septal splints with clip is more efficacious alternative to nasal packing in patients undergoing septoplasty. $\underline{\text { Keywords }}$

Nasal Septum; Septoplasty; Pain, Postoperative; Epistaxis; Headache

$\mathrm{T}$ The practice of packing the nose after septoplasty was thought to be indispensable in the past. This was a fundamental step to prevent septal haematoma, synechiae formation and of course, to prevent the post-operative bleeding and was supposed to stabilize the remaining cartilaginous and bony portion of the septum. ${ }^{1}$

Various packing materials have been used with or without lubricants and medications, like fingerstall packs, cotton gauze packs, paraffin packs, Telfa $\AA$, cuttings of the suction tube, cellulose and foam and now-a-days

1 - Department of ENT, K. D. Medical college, Mathura, U.P.

\section{Corresponding author:}

Dr Preeti Singh

email: Drpreeti_parihar@yahoo.co.in
Merocel ${ }^{\circledR}$ (a polymer made from hyaluronic acid).

Nasal packing apart from causing breathing distress, has resulted in epiphora, ${ }^{2}$ dysphagia, ${ }^{2}$ sleep disturbance, ${ }^{3}$ post-operative pain, ${ }^{4-6}$ headache, ${ }^{2}$ septal infection, septal abscess and even toxic shock syndrome. ${ }^{7}$

Different studies have been performed to compare different packing materials, with or without airway, but the complaints of post-operative pain has always been common to every type of packing material. ${ }^{8}$

The present study aims at comparative analysis of the outcome of nasal packing and septal splints with clip application after septoplasty. Various parameters e.g; postoperative pain, epiphora, dysphagia, dryness of mouth, haeadache, sleep disturbance, nasal bleeding, septal haematoma, nasal infections and adhesions are compared in both the modalities. 


\section{Materials and Methods}

The present study was carried out in the department of Otorhinolaryngology from January 2016 to October 2019 with a study population of 60 patients, who underwent septoplasty for deviated nasal septum. They were divided into three groups -

1) Group 1: Nasal packing was done in this group after septoplasty.

2) Group 2: Nasal septal clip with splints was applied postoperatively in this group and was removed after 1 day.

3) Group 3: Nasal septal clip with splints was applied in this group and was removed after 3 days.

\section{Technique of Nasal Packing:}

Group 1: Nasal packing was done after septoplasty in 30 patients and the pack was removed after 3 days.

Group 2: Septal clip was applied in 15 patients and removed after 1 day.

Group 3: Septal clip was applied in 15 patients who underwent septoplasty and it was removed after 3 days.

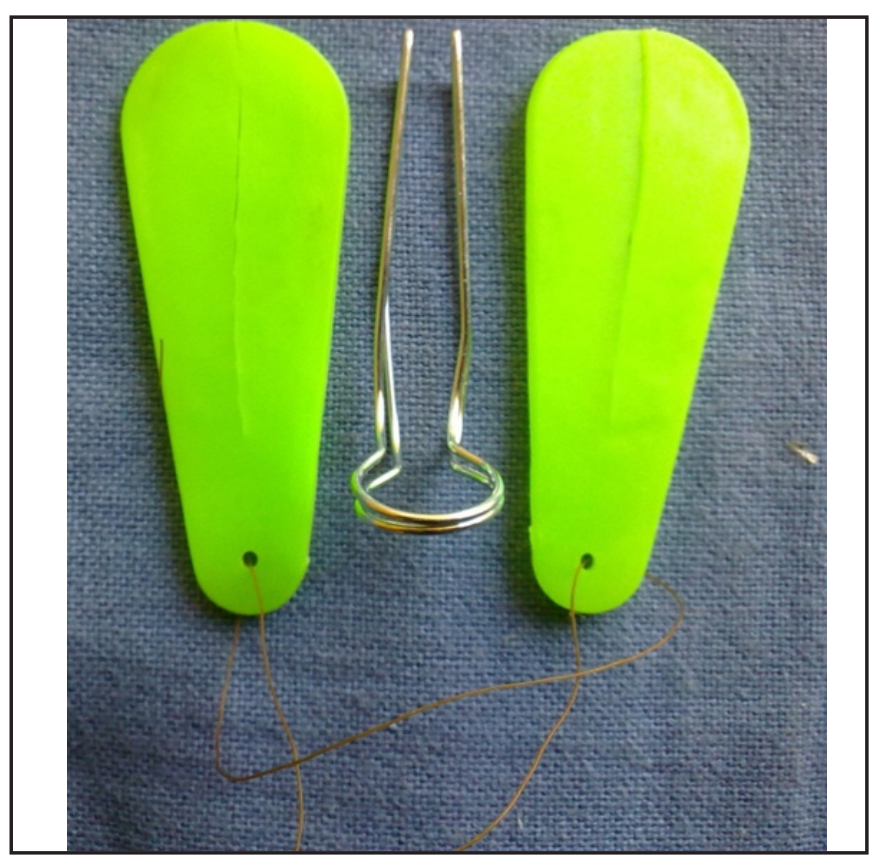

Fig. 1. Septal clip(septal splints are slit longitudinally and tied together at the anterior end.)
Either Bactigras ${ }^{\circledR}($ tulle gras dressing evenly impregnated with white soft paraffin containing chlorhexidine acetate $0.5 \% \mathrm{w} / \mathrm{w}$ ) or Merocel $\AA$ was used as packing material.

2-3 Bactigras ${ }^{\circledR}$ were folded together to fit the nasal cavity and nasal cavity was held open using a Killian's speculum and the Bactigras ${ }^{\circledR}$ was inserted using Tilley's aural forcep/nasal packing forcep.

Merocel ${ }^{\circledR}$ was similarly inserted into both the nasal cavities and antibiotic solution was injected into the merocel ${ }^{\circledR}$ to make it snuggly fit the nasal cavity.

\section{Application of Septal Splints with Clip:}

The spring clip is made from medical grade stainless steel wires.

Splints are made from polyethylene, they are incompletely slit in longitudinal direction. The anterior ends of the two splints are tied together with a silk thread to prevent posterior migration and to facilitate removal. (Fig.1)

Splints, after lubricating with Neosporin ${ }^{\circledR}$ ointment are inserted into both the nasal cavities along the septum

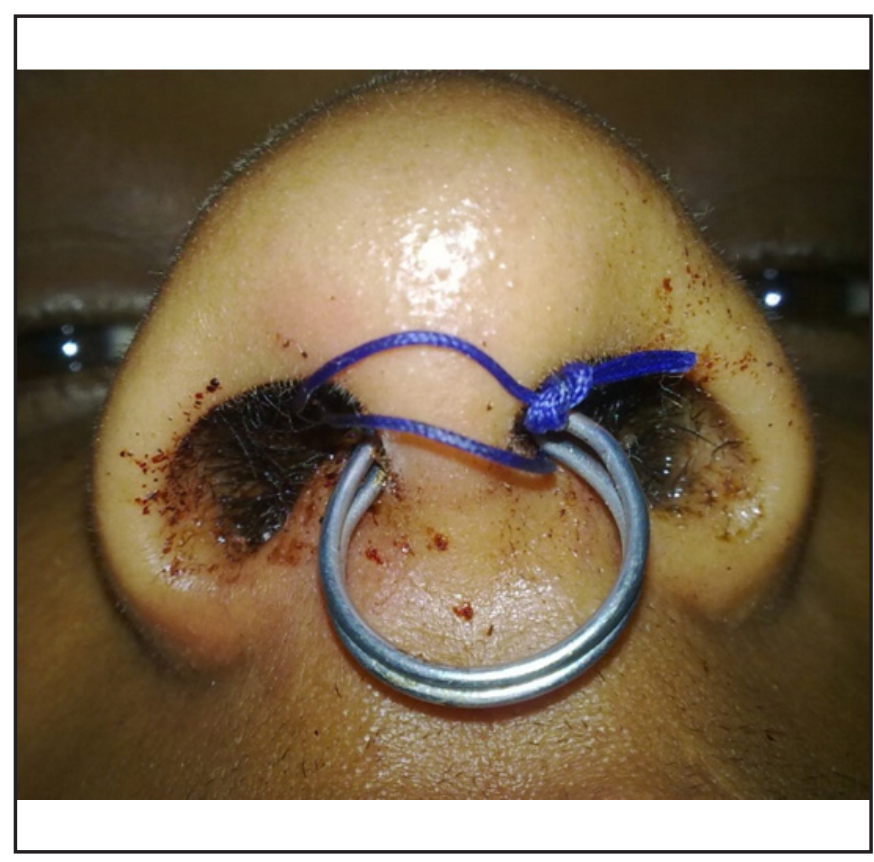

Fig. 2. Septal clip in place 
with the help of nasal packing forceps. The spring clip is held open with Hartmann nasal speculum and inserted into the nose to compress the splints and in turn approximate the mucosal flaps. (Fig. 2)

\section{Parameters compared}

Following parameters were compared:

Post-operative pain, Epiphora, Dysphagia, Dryness of mouth, Headache, Sleep disturbance, Hematoma, Infection/septal abscess/toxic shock syndrome, Pain while removing (pack/clip), Bleeding while removing(pack/clip), Synechiae, Perforation.

Complaints of post-operative pain, epiphora, dyphagia,dryness of mouth and headache were noted on the day of surgery (6hrs after surgery) and the complaints of sleep disturbance on the same night was asked for.

Other complications were noted at the time of removal of nasal pack (post-operative day 3) or septal clip(post-operative day 1 and day 3 ) and after 1 week and 6 weeks.

Patients in each group were followed-up postoperatively at following intervals:

1) 6 hours post-operatively for assessment of

a) Pain.

b) Presence or absence of epiphora.

c) Presence or absence of dysphagia.

d) Presence or absence of dryness of mouth.

e) Presence or absence of headache.

2) Patients were enquired about sleep disturbance on the night following surgery due to the nasal packing or the septal clip in place.

3) At the time of removal of septal clip(after 1 or 3 days)/nasal pack (after 3 days) for assessment of

a) Pain

b) Bleeding from the nose

c) Septal haematoma

d) Nasal infections

4) After 1 week and 6 weeks for assessment of

a) Presence or absence of nasal infection

b) Presence or absence of septal haematoma c) Presence or absence of synechiae formation

d) Presence or absence of septal perforation

The pain at $6^{\text {th }}$ postoperative hour and during removal of clip/pack was measured using visual analogue score.

Bleeding was considered to be present if any blood was noted to be coming out of anterior nares or if seen trickling over the posterior pharyngeal wall after removal of pack/clip.

Presence of septal hematoma, synechiae and perforation was determined by anterior rhinoscopy and diagnostic nasal endoscopy.

Local signs of nasal infection and septal abscess were looked for and nasal swab for culture sensitivity was sent in suspected cases.

Other parameters like intensity of pain, epiphora, dysphagia, dryness of mouth, headache and disturbed sleep were assessed by presenting a questionnaire to patients with specific questions for these symptoms.

\section{Results}

Out of total 60 patients $45(75 \%)$ were male and $15(25 \%)$ were female and highest prevalence was in age group of 11-20yr.This group had 32(53.33\%) of total 60 patients.

\section{Statistical calculations:}

Unpaired student t-test was applied for deriving the $\mathrm{p}$ value in case of postoperative pain (quantitative variable) at 6 th postoperative hour and during clip/pack removal.

For all other parameters (qualitative variables) chi square test was used.

P-value of 0.05 or less was considered statistically significant.

From the observed values of different parameters and calculated p-values applying different tests of significance following results are derived:

The mean pain score at 6 th postoperative hour (Table I) in nasal packing group (4.53) is significantly $(\mathrm{p}<.0001)$ higher than that in septal clip group (2.13). Epiphora (Table I) was present in 29 patients of nasal packing group and 3 patients of septal clip group at 
Table I: Parameters after 6 hours post-operatively

\begin{tabular}{|c|c|c|}
\hline & $\begin{array}{c}\text { GROUP } \\
1(\mathbf{N}=30)\end{array}$ & $\begin{array}{c}\text { GROUP2 } \\
\text { + GROUP3 } \\
\text { (N=30) }\end{array}$ \\
\hline $\begin{array}{c}\text { Mean Post-operative } \\
\text { pain(VAS) }\end{array}$ & 4.53 & 2.13 \\
\hline Epiphora (present in) & 29 & 3 \\
\hline $\begin{array}{c}\text { Dysphagia (present } \\
\text { in) }\end{array}$ & 24 & 3 \\
\hline $\begin{array}{c}\text { Dryness of mouth } \\
\text { (present in) }\end{array}$ & 30 & 4 \\
\hline Headache (present in) & 14 & 1 \\
\hline
\end{tabular}

Sleep disturbance on following night:

In Group 1- present in 25 subjects

In Group 2 + Group 3- present in 6 subjects

6th postoperative hour, the observed difference is statistically significant $(\mathrm{p}<0.001)$. Dysphagia (Table I) was present in 24 patients of nasal packing group and 3 patients of septal clip group at 6th postoperative hour, the observed difference is statistically significant $(\mathrm{p}<$ 0.001 ). Dryness of mouth (Table I) was present in 30 patients of nasal packing group and 4 patients of septal clip group at 6th postoperative hour, this difference also is statistically significant $(p<0.001)$. Headache was present in 14 patients of nasal packing group and 1 patients of septal clip group at 6th postoperative hour, this observation is statistically significant $(\mathrm{p}<0.001)$.

Sleep disturbance during the night following the surgery was present in 25 patients of nasal packing group and 6 patients of septal clip group $(\mathrm{p}<0.001)$.

Mean pain score at the time of removal of septal clip/ nasal pack (Table II) was 6.03 in nasal packing group (Group 1), 2.9 in septal clip group (Group $2+$ Group 3), 2.87 in group 2 and 2.93 in group 3.The observed difference in mean pain score between nasal packing and septal clip group is statistically significant $(\mathrm{p}<0.0001)$, while observed difference in mean pain score between group 2 and group 3 is statistically insignificant $(\mathrm{p}=0.46)$.

Nasal bleeding was present in 4 patients of nasal packing group, 1 patient of septal clip group 2 and 1 patient of septal clip group 3 at the time of removal of septal clip/nasal pack, the difference observed between nasal packing and septal clip group is statistically insignificant $(p=0.389)$. Synechiae were present in 3 patients of nasal packing group, none of the patients of septal clip group 2 and septal clip group 3, 1 week after surgery, the difference is statistically insignificant $(p=0.076)$. Septal perforation was present in 1 patient of nasal packing group, none of the patients of septal clip group 2 and septal clip group 3, 1 week and 6 weeks after surgery, this observation is also statistically insignificant $(\mathrm{p}=0.313)$.

\section{Discussion}

History of septal surgery can be traced back to $1800^{9}$, while functional surgery of the nose started in France at the turn of century where different types of nasal packing materials were used after nasal surgery. ${ }^{10}$

While life-threatening complications associated

Table II: Parameters at the time of removal septal clip/nasal pack

\begin{tabular}{|c|c|c|c|} 
& GROUP 1(N=30) & GROUP 2(N=15) & GROUP 3(N=15) \\
\hline Pain (VAS) & 6.03 & 2.87 & 2.93 \\
\hline Bleeding (present in) & 4 & 1 & 1 \\
\hline $\begin{array}{c}\text { Haematoma (present } \\
\text { in) }\end{array}$ & 0 & 0 & 0 \\
\hline Infection (present in) & 0 & 0 & 0 \\
\hline
\end{tabular}


with nasal packing have been documented, these complications occurred primarily in the setting of posterior packing placed for treatment of epistaxis. ${ }^{11}$ The presumed etiology of death in these cases, the nasopulmonaryreflex $1^{2-15}$ has not been reported in the modern literature of postseptoplasty packing.

The most common morbidity associated with packing in postseptoplasty patients is postoperative pain., ${ }^{4,6,7}$

Additionally postoperative infection including toxic shock syndrome, ${ }^{16}$ worsening of sleep disordered breathing, ${ }^{3}$ headache,epiphora,dysphagia,dryness of mouth $^{2,17}$ have been documented.

The most annoying clinical feature in this study was pain or discomfort due to the nasal pack or septal clip in place. Most common pain score at 6th postoperative hour was 4 in nasal packing group and 2 in septal clip group. The mean pain score at 6 th postoperative hour was 4.53 in nasal packing group and 2.13 in septal clip group. The mean pain score at the time of removal of nasal pack was 6.03 and at the time of removal of septal clip was 2.90.The difference was found to be statistically significant $(\mathrm{p}<0.0001)$.

Veluswamy et al. ${ }^{17}$ in their study on 80 subjects, noted mean pain score of 7.23 in packing group and 2.57 in septal clip group. They found that $28(70 \%)$ patients in the nasal packing group had VAS score 6 or above, $10(25 \%)$ patients had score of 10 . Only three patients of septal clip group had score more than 5,the most common score in this group was one (in $50 \%$ of patients).

In a study done by Schoenberg et $a .^{4}$ on 95 patients, the mean pain score in packed group was 4.2 and 2.8 in unpacked group, they found significantly greater extent of postoperative pain in the packed group, which is very similar to our observation.

Nunez et al. ${ }^{6}$ in their study on 59 patients, divided them into nasal packing group and quilting suture group. They recorded pain on visual analogue score on postoperative day one and found it to be significantly higher in packing group $(\mathrm{p}<0.05)$.

Ardenhali et al. ${ }^{18}$ in their study conducted on 114 patients who underwent septoplasty and were subsequently divided into packing and non- packing group, found the average VAS score 5 in packing group and 2.1 in non packing group which is very similar to that of our study.

Gunaydm et al. ${ }^{19}$ in their study on two hundred patients who underwent septoplasty, divided them into nasal pack and transseptal suture group. 75 patients $(76.5 \%)$ in the transseptal suture group had postoperative pain scores of 0 or 1 ,whereas 89 patients $(89 \%)$ in the nasal pack group had scores of 2,3 or 4.Nasal packing was found to be significantly more painful than transseptal sutures $(\mathrm{p}<0.001)$.

Epiphora is one of the common complaints of the patient whose nose is packed and it occurs due to blockage of nasolacrimal duct opening caused by pressure from nasal pack. We observed that epiphora was present in $29(97 \%)$ of 30 patients in nasal packing group while in the septal clip group it was present only in $3(10 \%)$ of the 30 patients. This observed difference was found to be statistically significant on applying chisquare test $(\mathrm{p}<0.001)$

The dysphagia is due to the Toynbee phenomenon i.e; during swallowing with the nasal pack in place, the air is forced into the middle ear as it cannot pass through the choana causing discomfort to the patient while swallowing. In our study we observed that dysphagia was complained by $24(80 \%)$ of the 30 patients in nasal packing group while it was present only in $3(10 \%)$ of the 30 patients in the septal clip group. The difference observed was found to be significant statistically $(\mathrm{p}<0.001)$ on applying chi-square test.

Dryness of mouth occurs in patients with packed nose due to drying effect of mouth breathing on oral, oropharyngeal and laryngeal mucosa. In our study we observed that all the $30(100 \%)$ patients in nasal packing group and $4(13.33 \%)$ patients in septal clip group complained of dryness of mouth. The observed difference was found to be significant statistically $(p<0.001)$ on applying chi-square test.

Presence or absence of headache at 6th postoperative hour in both the groups was compared. In our study $14(47.67 \%)$ patients in the nasal packing group complained of headache while $1(3.33 \%)$ patient in the septal clip group complained of headache. This observed difference between the two groups was also found to be significant statistically $(\mathrm{p}<0.001)$ on applying chi- 
square test.

Patients were asked about any sleep disturbance they experienced due to nasal pack or septal clip in place on the night following surgery and we found that 25 $(83.33 \%)$ patients in nasal packing group and $6(20 \%)$ patients in the septal clip group experienced sleep disturbance. This observed difference was found to be statistically significant $(\mathrm{p}<0.001)$

Awan et al. ${ }^{2}$ in their study on 88 patients who underwent septoplasty, divided them into packing and no packing group(in this group septal quilting sutures were applied). They found most common pain score to be 10 in packing group and 1 in non-packing group. They also found higher incidence of headache, epiphora, dysphagia, sleep-disturbance, septal hematoma and adhesions in packing group.

Veluswamy et al. ${ }^{17}$ in their study on 80 subjects, found higher incidence of headache, epiphora, dysphagia, dryness of mouth, bleeding and in nasal packing group when compared to septal clip group.

Postoperative nasal bleeding is one of the main concern why many ENT surgeons are still favourably inclined to packing the nose post-septoplasty. We observed the incidence of nasal bleed at the time of nasal pack/septal clip removal. Any blood coming out of the nostrils or trickling over the posterior pharyngeal wall was considered as nasal bleeding present.

In our study we observed that nasal bleeding was present in $4(13.33 \%)$ patients of nasal packing group(Group 1) and 2(6.67\%) patients of septal clip group. In the septal clip group further subdivision was made based on whether septal clip was removed after 1 day (Group 2) or after 3 days(Group 3). One case of nasal bleeding was present in each of groups 2 and 3 . On applying chi-square test the observed difference in the incidence of nasal bleeding between nasal packing group and septal clip group was found to be statistically insignificant. $(\mathrm{p}=0.389)$.

Most of earlier studies suggest that only few patients (if any at all) will require post-septoplasty nasal packing to prevent nasal bleeding and it is not justified to routinely pack patient's nose after septoplasty in light of little advantage and much more distress caused by the nasal pack. But most of the above studies do suggest that nasal bleeding was more common in no-packing group than in packing group even though statistical significance was not reached.

No septal hemaetoma or nasal infections were noted in any of the group at the time of removal of nasal pack/ septal clip, after 1 week and after 6 weeks.

The patients were assessed for presence or absence of synechiae formation at postoperative interval of 1 week and 6 weeks. Three $(10 \%)$ patients of the nasal packing group had synechiae after 1 week which were released and no synechiae were observed in any patient at 6weeks, while no synechiae were observed even at 1 week in septal clip group patients. The observed difference in synechiae formation between two groups did not reach statistical significance. $(p=0.076)$.

We found only one patient with septal perforation, who was in nasal packing group. This observation was statistically insignificant. $(\mathrm{p}=0.313)$

\section{Conclusion}

Septal splints with clip is more efficacious alternative to nasal packing in patients undergoing septoplasty.

\section{References}

1. Dubin MR, Pletcher SD. Postoperative packing after septoplasty:is it necessary? Otolaryngology Clin North Am. 2009; 42:279-85

2. Awan MS, Iqbal M. Nasal packing after septoplasty: A randomized comparison of packing versus no packing in 88 patients.ENT Journal November 2008; 87(11):624-7

3. Taasan V, Wynne JW, Cassisi N, et al. The effect of nasal packing on sleep-disordered breathing and nocturnal oxygen desaturation. Laryngoscope 1981;91:1163-72

4. Von Schoenberg M, Robinson P, Ryan R. Nasal packing after routine nasal surgery-is it justified? J Laryngol Otol. 1993;107:902-5

5. Nunez DA, MartinFW. An evolution of post-operative packing in nasal septalsurgery. Clin Otolaryngol. 1991;16:549-50

6. Samad I, Stevens HE, Maloney A. The efficacy of nasal septalsurgery.J Otolaryngol. 1992; 21:88-91

7. Jacbson JA, Kasworm EM. Toxic shock syndrome after nasal surgery. Case reports and analysis of risk factors. Arch Otolaryngol Head Neck Surg. 1986;112(3):329-32

8. Illum P, Grymer L, Hilberg O.Nasal packing after septoplasty Clin Otolaryngol.1992;17:158-62 
9. Willemot J. History of Rhinology; Functional Surgery of Nose in France at the turn of the century.Rhinology1990; 28:275-80

10. Tardy Jr ME. Chronic Rhinitis and Nasal Obstruction. In: Ballenger JJ ed. Diseases of the Nose Throat Ear, Head and Neck.14th ed. Philadelphia Lea and Firbiger,1991; 24-78

11. Fairbanks DNF. Complications of nasal packing. Otolaryngology Head Neck Surgery 1986; 94:412-5

12. Angell James JE. Nasal Reflexes. Proc R Soc Med.1969; $62: 1287-93$

13. Ogura JH, Harvey JE, Nasopulmonary mechanics-experimental evidence of the influence of upper airway upon the lower. Acta Otolaryngol. 1971;71:123-32

14. Ogura JH, Togawa K, Dammkochlear R. Nasal obstruction and the mechanics of breathing. Physiologic relationships and the effects of nasal surgery. Arch Otolaryngol.1966;83:135-50

15. Cassisi NJ, Biller HF, Ogura JH. Changes in arterial oxygen tension and pulmonary mechanics with the use posterior packing in epistaxis. Laryngoscope 1971;81:1261-6

16. Toback J, Fayerman JW. Toxic shock syndrome following septorhinoplasty. Arch otolaryngol. 1983;109:627-9

17. Veluswamy A, Handa S, Shivaswamy S. Nasal Septal Clips: An Alternative to Nasal Packing After Septal Surgery? Indian J Otolaryngol Head Neck Surg. DOI 10.1007/s12070-011-03882.

18. Ardenhali MM, Bastaninejad S. Use of nasal packs and intranasal septal splints following septoplasty. Int J. Oral Maxillofacial Surg. 2009

19. Gunaydm RO, Aygenc E, Selma K, Fidan F, Celikkanat S. Nasal packing and transseptal suturing techniques: surgical and anaesthetic perspectives. Eur Arch Otorhinolaryngol. 2011; 268:1151-6. DOI 10.1007/s00405-011-1542-x. 